\title{
Burden and consequence of birth defects in Nepal-evidence from prospective cohort study
}

Prajwal Paudel ${ }^{1}$, Avinash K. Sunny ${ }^{2} \mathbb{B}$, Rejina Gurung ${ }^{2} \mathbb{D}$, Abhishek Gurung ${ }^{2}$, Honey Malla², Netra B. Rana ${ }^{3}$, Nawaraj $\mathrm{KC}^{4}$, Ram Narayan Chaudhary ${ }^{5}$ and Ashish $\mathrm{KC}^{6^{*}}$ (I)

\begin{abstract}
Background: Every year an estimated 7.9 million babies are born with birth defect. Of these babies, more than 3 million die and 3.2 million have disability. Improving nationwide information on prevalence of birth defect, risk factor and consequence is required for better resource allocation for prevention, management and rehabilitation. In this study, we assess the prevalence of birth defect, associated risk factors and consequences in Nepal.

Method: This is a prospective cohort study conducted in 12 hospitals of Nepal for 18 months. All the women who delivered in the hospitals during the study period was enrolled. Independent researchers collected data on the social and demographic information using semi-structured questionnaire at the time of discharge and clinical events and birth outcome information from the clinical case note. Data were analyzed on the prevalence and type of birth defect. Logistic regression was done to assess the risk factor and consequences for birth defect.
\end{abstract}

Results: Among the total 87,242 livebirths, the prevalence of birth defects was found to be 5.8 per 1000 live births. The commonly occurring birth defects were anencephaly (3.95\%), cleft lip (2.77\%), cleft lip and palate (6.13\%), clubfeet (3.95\%), eye abnormalities (3.95\%) and meningomyelocele (3.36\%). The odds of birth defect was higher among mothers with age $<20$ years (adjusted Odds ratio (aOR) 1.64; 95\% Cl, 1.18-2.28) and disadvantaged ethnicity (aOR 1.78; 95\% Cl, 1.46-2.18). The odds of birth asphyxia was twice fold higher among babies with birth defect (aOR 1.88; 95\% Cl, 1.41-2.51) in reference with babies without birth defect. The odds of neonatal infection was twice fold higher among babies with birth defect (aOR 1.82; 95\% Cl, 1.12-2.96) in reference with babies without birth defect. Babies with birth defect had three-fold risk of pre-discharge mortality (aOR 3.00; 95\% Cl, 1.93-4.69).

Conclusion: Maternal age younger than 20 years and advantaged ethnicity were risk factors of birth defects. Babies with birth defect have high risk for birth asphyxia, neonatal infection and pre-discharge mortality at birth. Further evaluation on the care provided to babies who have birth defect is warranted.

Funding: Swedish Research Council (VR).

Keywords: Birth defects, Nepal, Prevalence, Risk factor, Mortality

\footnotetext{
* Correspondence: ashish.k.c@kbh.uu.se

${ }^{6}$ Department of Women's and Children's Health, Uppsala University, Dag Hammarskjölds väg 14B, Uppsala, Sweden

Full list of author information is available at the end of the article
}

(c) The Author(s). 2021 Open Access This article is licensed under a Creative Commons Attribution 4.0 International License, which permits use, sharing, adaptation, distribution and reproduction in any medium or format, as long as you give appropriate credit to the original author(s) and the source, provide a link to the Creative Commons licence, and indicate if changes were made. The images or other third party material in this article are included in the article's Creative Commons licence, unless indicated otherwise in a credit line to the material. If material is not included in the article's Creative Commons licence and your intended use is not permitted by statutory regulation or exceeds the permitted use, you will need to obtain permission directly from the copyright holder. To view a copy of this licence, visit http://creativecommons.org/licenses/by/4.0/ The Creative Commons Public Domain Dedication waiver (http://creativecommons.org/publicdomain/zero/1.0/) applies to the data made available in this article, unless otherwise stated in a credit line to the data. 


\section{Introduction}

Birth defects are anomalies in morphogenesis during early foetal life resulting in structural, behavioural, functional and metabolic disorders that can be detected prenatally, at birth or later in infancy [1]. Globally, more than 3 million babies with birth defect die within the first 28 days of life and a majority of the survivors suffer with disabilities $[2,3]$. Lower- and middle-income countries (LMIC) carry the major burden (>90\%) of these anomalies which are least prioritized as compared to other causes of neonatal and infant mortality for prevention and management $[2,3]$. There is a high risk of mortality due to congenital heart disease and neural tube defects globally $[2,4]$.

South-East Asia has higher prevalence of cleft lip and palate [5], whereas neural tube defects is highly prevalent in Mexico, Central America, and India [3]. In Nepal in 2010, among the estimated 600,000 born 40,000 births were are born with malformations with cleft lip and palate, neural tube defects, congenital heart disease as the commonest conditions $[5,6]$. The prevalence of birth defect is widely variable ranging from 0.3 to $7 \%$ implicating various known and unknown factors interplaying differently in varied time and geographical location [7]. Often, these factors are recognised as genetic in origin (10-30\%), environmental (5-10\%), multi-factorial (2035\%) and unknown (30-45\%) [8]. Primarily these factors may affect the developing foetal organs during the first trimester while undergoing crucial stages of formation passing through stages of fertilization, implantation and organ formation $[1,8]$. Identification of several maternal factors for birth defects like maternal age, lack of nutritious diet, no use of peri-conceptional folic acid, alcohol and tobacco consumption, exposure to pesticides and Xrays, and infection signifies the role of effective antenatal care (ANC) counselling and screening $[9,10]$.

To the best of the present evidence, therapy, medication, surgery, or assistive technology are different services available for management of birth defects and in most cases essential paediatric surgery can avert early mortality and long-term disability [11]. The Human capital approach to repair cleft lip and Palate in LMICs and favourable outcomes in High income Countries (HICs) in Gastrointestinal and other anomalies have refuted the traditional perception about Paediatric surgery [12]. Prenatal diagnostic techniques, genetic counselling, and access to termination of Pregnancy remain the cornerstone to curtail neonatal mortality and still birth [13].

In LMICs, lack of diagnostic and national screening programmes has led to paucity of nationally representative data, a major hurdle for in-depth understanding of the epidemiology [14]. In Nepal, no protocol regarding management and timely service provision to babies born with birth defects exists except for sporadic programmes for cleft lip and palate repair or few organisations providing care to disabled children. To further accelerate the reduction of 2016 neonatal mortality rate of 21 per 1000 live births to achieve SDG target of 12 per 1000 live birth, intervention to prevent birth defect and manage them is important $[15,16]$. This study can be a basis for National Birth defect Surveillance Registry and thereafter, developing prevention and management guidelines on birth defects. The current study provides evidence on prevalence, patterns, factors and outcomes associated with birth defects across the 12 hospitals in Nepal.

\section{Method}

\section{Study design and setting}

A prospective cohort study was conducted in 12 public hospitals across Nepal to evaluate the efficacy of scale up of Helping Babies Breathe Quality Improvement Project from 1 July 2017 to 17 October 2018 [17]. The total birth in cohort constituted 15\% of total birth (home and health facility) taking place in Nepal. The hospitals were selected from different geographic locations across the country, representing different maternal and child health services. Standard ANC services include at least four antenatal check-ups (first at the fourth month, second at the sixth month, third at the eighth month, and fourth at the ninth month of pregnancy); monitoring of blood pressure, weight, and fetal heart rate; provision of information, education, and communication; behavior change communication for danger signs and care during pregnancy; detection and management of complications; and provision of tetanus toxoid immunization, iron tablets, and malaria prophylaxis where necessary. All the hospitals were referral level public hospitals with more than 1000 deliveries per year.

\section{Study participants}

All babies born in the 12 hospitals during the study period were selected for this study. Structural birth defect (cleft lip, cleft lip and palate, congenital heart diseases and defects of gastro intestinal tract or CNS and genetic and chromosomal disorders) categorized as birth defect in the hospital registry was included as birth defect. Stillborn babies, out-born babies and babies whose mothers did not consent or avail themselves were excluded from the study.

\section{Data collection and management}

In the selected hospitals, a data surveillance system, including data collectors and data coordinators, was setup for collection of data on the mothers and newborns. Obstetric data were collected through patient files and maternity register in the maternity wards using a data retrieval form. Socio-demographic data were collected through face-to-face interviews with mothers before 
discharge. Semi-structured interviews were conducted. Data coordinator assess the completed forms for completeness, which are then indexed, sealed and sent to the head office for further action. In the central office, the data management team, led by a data manager, sort, index, file and reassess for completeness. Data entry operators enter the indexed forms based on the hospitals in Census and Survey Processing System (CSPro). The entered data are cleaned and exported to Statistical Package for the Social Sciences (SPSS) for further data analysis.

\section{Variables in the study for analysis}

Liveborn babies with birth defects were the variable of interest for this study. Demographic variables included age of mother (less than 20 years, 20 to 35 years and 35 years or/and above), ethnicity (brahmin-chettri, relatively advantaged group and others, relatively disadvantaged group), education (literate and illiterate) type of fuel used for cooking in household (clean or polluted) and smoking habit. Antenatal variables included antenatal care (ANC) check-up by doctor/nurse and timing of first ANC visit (first, second or third trimester), parity of mothers ( 0 previous birth, 1 previous birth and 2 or more previous birth) and severe anemia during pregnancy $(7.5 \mathrm{mg} / \mathrm{dl})$. Intrapartum variables included multiple deliveries and sex of the baby. Low birth weight was defined as birth weight less than $2500 \mathrm{~g}$. Birth asphyxia was defined as apgar score less than 7 at $1 \mathrm{~min}$. Neonatal infection was defined as clinical signs of infections at admission to sick newborn care units. Predischarge mortality included deaths of newborn with birth defects before discharge.

\section{Statistical analysis}

Prevalence of birth defects was calculated based on the total number of congenital cases reported and total number of live births in the same period. Crosstabulation was done for socio-demographic, obstetric and neonatal characteristics. Binary logistic regression was performed to analyze the level of association between the characteristics and birth defects. The significance was determined at $p<0.05$. All variables with $p<$ 0.2 in the univariate analysis were considered for multivariable logistic regression analysis.

\section{Ethical consideration}

All mothers were consented in written before the start of the data collection and confidentiality was maintained. Ethical approval was received from Ethical Review Board of Nepal Health Research Council (reference number 26-2017).

\section{Results}

Out of the total 104,223 admissions, a total of 87,989 deliveries were conducted during the study period of which 87,242 deliveries were live births and 747 deliveries were stillbirths. Among them, there were 506 reported cases of birth defects (Fig. 1). The prevalence of birth defects was found to be 5.8 per 1000 live births. The different types of birth defects as reported from the data show anencephaly (3.95\%), cleft lip (2.77\%), cleft and palate (6.13\%), clubfeet (3.95\%), eye abnormalities (3.95\%) and meningomyelocele (3.36\%). Most (75.89\%) of the reported cases have not been classified (Fig. 2).

Univariate analysis showed significant association with birth defects for most of the socio-demographic, obstetric and neonatal characteristics. Socio-demographic characteristics such as ethnicity and type of fuel used for cooking in the household showed significant association $(<0.001)$ with birth defects. Female child was significantly associated with birth defects $(p=0.002)$. Women with one previous birth $(p=0.002)$ and two or more birth $(<0.001)$ were significantly associated with birth defects. Multiple delivery was significantly associated with birth defects $(p=0.02)$. (Table 1$)$.

Multivariate analysis showed significant association for various factors with birth defects. Mothers less than 20 years of age were 1.64 times more likely (aOR 1.64; 95\% CI, $1.18-2.28, p$-value $=0.003)$ to be associated with birth defects compared to mothers $20-<35$ years of age. Mothers of ethnicity other than Brahmin/Chhetri were 1.78 times more likely (aOR 1.78; 95\% CI, 1.46-2.18, $p$ value $=<0.001$ ) to have babies with birth defects. Female child had 1.35-fold risk (aOR 1.35; 95\% CI, 1.13-1.61, $p$ value $<0.001$ ) of having birth defects compared to male child. Compared to women with no previous birth, the risk of birth defect was higher among women with 1 previous birth (aOR 1.58; 95\% CI, 1.26-1.98; $p<0.001$ ) and women with 2 or more previous birth (aOR 2.33; 95\% CI, 1.84-2.95; $p<0.001$ ). Also, mothers with multiple deliveries had 1.8-fold risk of having babies with birth defect compared to mothers with single deliveries (aOR 1.8; 95\% CI, 0.98-3.28; $p=0.06$ ). (Table 2).

In a multi-variable analysis, babies with birth defect have 1.88 -fold risk of birth asphyxia (aOR 1.88; $95 \% \mathrm{CI}$, $1.41-2.51 ; p<0.001)$ in reference with babies without birth defect. Babies with birth defect have 1.82-fold risk of neonatal infection (aOR 1.82; 95\% CI, 1.12-2.96; $p<$ 0.02 ). The risk of pre-discharge mortality for babies with birth defects was 3.31 folds (cOR 3.31; 95\% CI, 2.135.14; $\mathrm{p}<0.001$ ) higher compared to babies without any birth defects (Table 3 ).

\section{Discussion}

The prevalence of birth defects in the present study is $0.58 \%$ which is comparable with the earlier studies in 

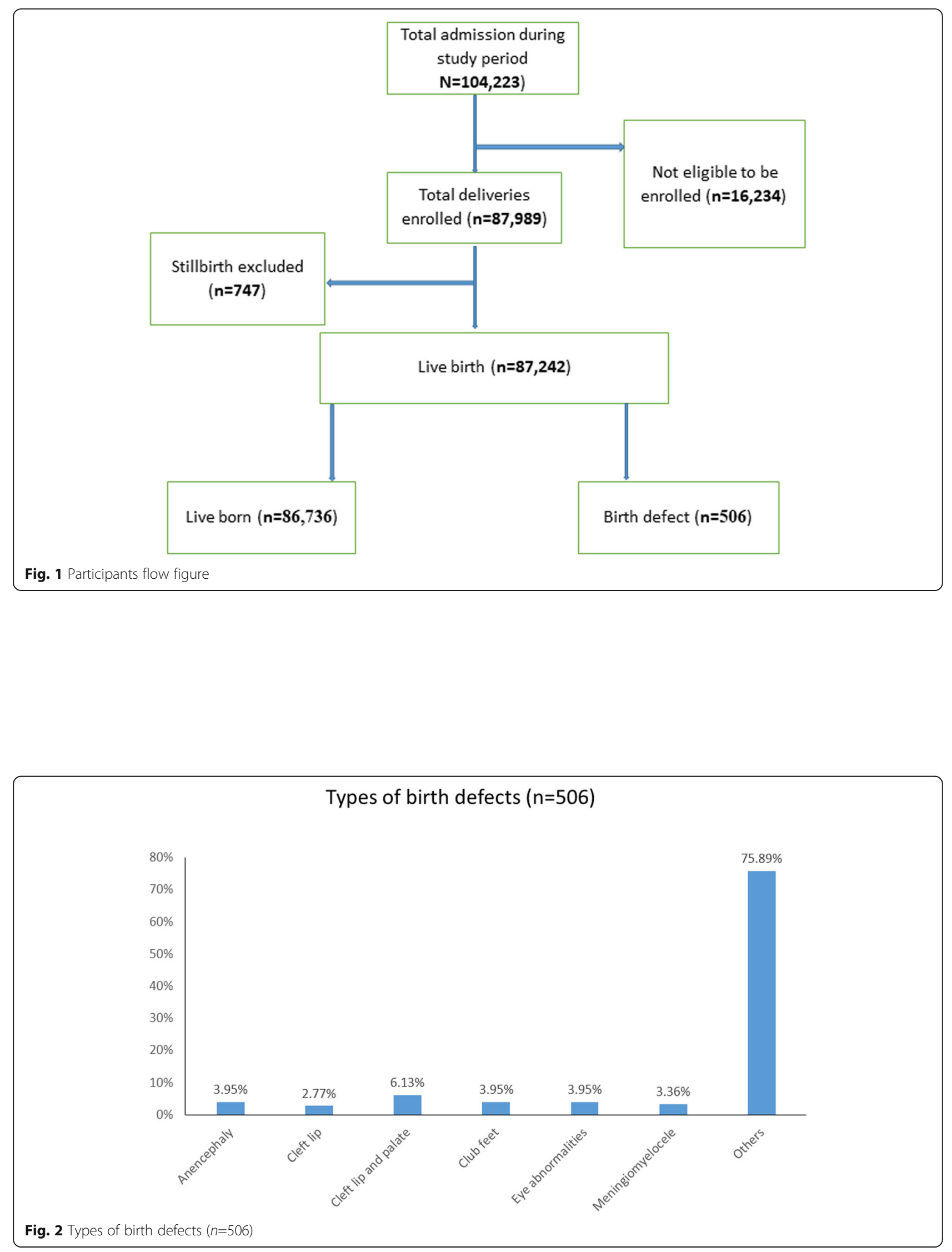
Table 1 Socio-demographic, obstetric and neonatal characteristics

\begin{tabular}{|c|c|c|c|c|c|}
\hline Variables & Birth defect & No Birth defect & Total & cOR $(95 \% \mathrm{Cl})$ & $p$-value \\
\hline \multicolumn{6}{|l|}{ Age of mother $(n=87,112)$} \\
\hline$<20$ years & $47(9.3 \%)$ & $6604(7.6 \%)$ & $6651(7.6 \%)$ & $1.25(0.93-1.69)$ & 0.15 \\
\hline 20-35 years & $442(87.4 \%)$ & $77,722(89.7 \%)$ & $78,164(89.7 \%)$ & Ref & \\
\hline$>35$ years & $17(3.4 \%)$ & $2280(2.6 \%)$ & $2297(2.6 \%)$ & $1.31(0.81-2.13)$ & 0.28 \\
\hline \multicolumn{6}{|l|}{ Literacy $(n=66,949)$} \\
\hline Illiterate & $19(6.0 \%)$ & $3063(4.6 \%)$ & $3082(4.6 \%)$ & $1.31(0.83-2.1)$ & 0.249 \\
\hline Literate & $300(94.0 \%)$ & $63,567(95.4 \%)$ & $63,867(95.4 \%)$ & Ref & \\
\hline \multicolumn{6}{|l|}{ Ethnicity $(n=87,112)$} \\
\hline Brahmin/Chhetri (relatively advantaged group) & $131(25.9 \%)$ & $33,897(39.1 \%)$ & $34,057(39.1 \%)$ & Ref & \\
\hline Others (relatively disadvantaged group) & $375(74.1 \%)$ & $52,709(60.9 \%)$ & $53,147(60.9 \%)$ & $1.84(1.51-2.25)$ & $<0.001$ \\
\hline \multicolumn{6}{|l|}{ Smoking $(n=66,949)$} \\
\hline No & $297(93.1 \%)$ & 60,869 (91.4\%) & $61,166(91.4 \%)$ & Ref & \\
\hline Yes & $22(6.9 \%)$ & $5761(8.6 \%)$ & $5783(8.6 \%)$ & $0.78(0.51-1.21)$ & 0.268 \\
\hline \multicolumn{6}{|l|}{ Type of fuel $(n=66,722)$} \\
\hline Polluted & $142(45.1 \%)$ & $16,283(24.5 \%)$ & $16,425(24.6 \%)$ & $2.53(2.02-3.16)$ & $<0.001$ \\
\hline Clean & $173(54.9 \%)$ & $50,124(75.5 \%)$ & $50,297(75.4 \%)$ & Ref & \\
\hline \multicolumn{6}{|l|}{ Sex of the baby $(n=87,112)$} \\
\hline Boy & $239(47.2 \%)$ & $46,836(54.1 \%)$ & $47,129(54.0 \%)$ & Ref & \\
\hline Girl & $267(52.8 \%)$ & $39,770(45.9 \%)$ & 40,037 (46.0\%) & $1.32(1.10-1.57)$ & 0.002 \\
\hline \multicolumn{6}{|l|}{ Parity $(n=87,101)$} \\
\hline Nullipara & $172(34.1 \%)$ & $39,882(46.1 \%)$ & $40,054(46.0 \%)$ & Ref & \\
\hline Primipara & $183(36.2 \%)$ & $30,472(35.2 \%)$ & 30,655 (35.2\%) & $1.39(1.13-1.72)$ & 0.002 \\
\hline Multipara & $150(29.7 \%)$ & $16,242(18.8 \%)$ & $16,392(18.8 \%)$ & $2.14(1.72-2.67)$ & $<0.001$ \\
\hline \multicolumn{6}{|l|}{ ANC check-up by doctor/nurse $(n=66,949)$} \\
\hline Yes & $316(99.1 \%)$ & $66,015(99.1 \%)$ & $66,331(99.1 \%)$ & Ref & \\
\hline No & $3(0.9 \%)$ & $615(0.9 \%)$ & $618(0.9 \%)$ & $1.02(0.33-3.19)$ & 0.974 \\
\hline \multicolumn{6}{|l|}{ Time for first ANC visit $(n=66,331)$} \\
\hline First trimester & $189(59.8 \%)$ & $29,594(44.8 \%)$ & $29,783(44.9 \%)$ & $1.68(1.15-2.46)$ & 0.008 \\
\hline Second trimester & $96(30.4 \%)$ & $28,276(42.8 \%)$ & $28,372(42.8 \%)$ & $0.89(0.59-1.34)$ & 0.58 \\
\hline Third trimester & $31(9.8 \%)$ & 8145 (12.3\%) & $8176(12.3 \%)$ & Ref & \\
\hline \multicolumn{6}{|l|}{ Severe anemia during pregnancy $(n=6002)$} \\
\hline No & $28(96.6 \%)$ & $5804(97.2 \%)$ & $5832(97.2 \%)$ & Ref & \\
\hline Yes & $1(3.4 \%)$ & $169(2.8 \%)$ & $170(2.8 \%)$ & $1.23(0.17-9.07)$ & 0.841 \\
\hline \multicolumn{6}{|l|}{ Multiple delivery $(n=87,112)$} \\
\hline No & 495 (97.8\%) & 85,667 (98.9\%) & $86,162(98.9 \%)$ & Ref & \\
\hline Yes & $11(2.2 \%)$ & 939 (1.1\%) & 950 (1.1\%) & $2.03(1.11-3.69)$ & 0.02 \\
\hline
\end{tabular}

Iraq and Iran which reported an incidence of 0.69 and $0.36 \%$ [18-20]. The patterns of system involved in our study show Musculoskeletal System to be most commonly affected presenting as cleft lip, cleft palate and club feet. This was in line with the study conducted in different parts of world in Egypt and India [21, 22]. A study in Iran and India reported higher prevalence of malformations from CNS, Cardiovascular system or
Gastrointestinal system [23, 24]. This variation in patterns could possibly be explained by various genetic and environmental factors interplaying differently in varied time and geographical location [10].

Mothers of age group less than 20 years were found to have risk of delivering a newborn with birth defect which was similar to the study which concluded association between young mothers and congenital anomaly 
Table 2 Multivariate analysis of risk factors associated with Birth defects $(n=66,123)$

\begin{tabular}{|c|c|c|}
\hline & aOR (95\% C.I.) & p-value \\
\hline \multicolumn{3}{|l|}{ Age of mother } \\
\hline $20-<35$ years & Reference & \\
\hline$<20$ years & $1.64(1.18-2.28)$ & 0.003 \\
\hline$>35$ years & $0.94(0.57-1.54)$ & 0.79 \\
\hline \multicolumn{3}{|l|}{ Ethnicity } \\
\hline Brahmin/Chhetri (relatively advantaged group) & Reference & \\
\hline Others (relatively disadvantaged group) & $1.78(1.46-2.18)$ & $<0.001$ \\
\hline \multicolumn{3}{|l|}{ Type of fuel } \\
\hline \multicolumn{3}{|l|}{ Clean } \\
\hline Polluted & $2.26(1.80-2.84)$ & $<0.001$ \\
\hline \multicolumn{3}{|l|}{ Sex of the baby } \\
\hline Boy & Reference & \\
\hline Girl & $1.35(1.13-1.61)$ & 0.001 \\
\hline \multicolumn{3}{|l|}{ Parity } \\
\hline Nullipara & Reference & \\
\hline Primipara & $1.58(1.26-1.98)$ & $<0.001$ \\
\hline Multipara & $2.33(1.84-2.95)$ & $<0.001$ \\
\hline \multicolumn{3}{|l|}{ Multiple delivery } \\
\hline No & Reference & \\
\hline Yes & $1.80(0.98-3.28)$ & 0.06 \\
\hline Constant & 0.002 & $<0.001$ \\
\hline
\end{tabular}

aOR adjusted Odds Ratio

[25]. In contrast, several studies have identified the potential of maternal age above 35 years in the causation of this condition [10, 26]. Developmental and behavioural factors like poor diet, illicit drug use, smoking etc. in the adolescent group as compared to older mothers relative to conception could likely affect the developing foetus [25].

According to different literatures, congenital malformation is seen in twins rather than singleton pregnancy [10, 27]. Likewise, our finding enlisted this study as one among those many. However, multiple delivery did not pose a risk to birth defect in Europe [28]. Alterations of the blood flow within the vascular anastomoses supplying the twins and early primary abnormality that might develop during twinning itself can lead to birth defects [29].
In comparison to women with no previous birth, the likelihood of giving birth to a baby with congenital defect was seen among women with 1 or more previous birth in our study, which is similar to those reported in other studies $[25,30]$. To the contrary, positive association between nulliparity and range of birth defects have also been successfully investigated earlier [31, 32]. The decrement in body nutrients stores among mothers who have previously delivered as compared to those who have never delivered a baby before explains the association between parity and congenital birth defects [33].

With regards to ethnicity, advantageous ethnic groups like Brahmin and Chettri were comparatively less likely to be associated with birth defects than the nonadvantageous group. Association of ethnicity with birth

Table 3 Consequences among babies with birth defects

\begin{tabular}{|c|c|c|c|c|c|c|}
\hline Variables & Birth defect & No Birth defect & $p$-value & COR $(95 \% \mathrm{Cl})$ & aOR $(95 \% \mathrm{CI})^{\mathrm{a}}$ & $p$-value \\
\hline Low birth weight $(n=14,676)$ & $99(0.7 \%)$ & Ref & 0.18 & $1.17(0.93-1.45)$ & $1.15(0.92-1.44)$ & 0.23 \\
\hline Birth asphyxia $(n=4971)$ & $53(1.1 \%)$ & Ref & $<0.001$ & $1.94(1.46-2.59)$ & $1.88(1.41-2.51)$ & $<0.001$ \\
\hline Neonatal infection $(n=1462)$ & $17(1.2 \%)$ & Ref & 0.004 & $2.05(1.26-3.33)$ & $1.82(1.12-2.96)$ & 0.02 \\
\hline Pre-discharge mortality ( $n=1149)$ & $21(1.8 \%)$ & Ref & $<0.001$ & $3.31(2.13-5.14)$ & $3.00(1.93-4.69)$ & $<0.001$ \\
\hline
\end{tabular}

adjusted with age of mother, sex of the baby, parity and multiple delivery 
defects has been depicted in the previously done studies $[25,34]$. Ethnic variance as the risk for malformations may be linked to genetic susceptiveness or to sociocultural and economic differences that might modify exposures [35].

This study showed that there was significant impact for female sex in regards to the causation of congenital birth anomalies and this significance is also supported by studies from neighbouring nations [36]. In contrast, male babies were found to have risk for birth defects in another study $[36,37]$. This variation could probably be explained by potential of the hormonal hypothesis of sex ratio explaining the unusual concentrations of hormones during or preceding pregnancy could be more common in those malformations with established sex ratio biases [38].

Studies have documented that conditions like cleft lip and polydactyly are more common in males whereas neural tube defects and cleft palate are more seen among female babies $[39,40]$. The high incidence of cleft palate and NTDs could also explain female preponderance to for birth defects. However, as we have not examined population-based resources in this study, this might not potentially explain the exact sex difference patterns in babies with congenital birth anomalies.

Babies with birth defects tend to have morbidities such as birth asphyxia and neonatal infection as found in this study. The risk of mortality among these babies at birth is higher similarly. Increased mortality arising from birth defects has also been identified in India [41]. This can be explained based on the type of defect or anomalies which describes the intensity or level of risk associated.

\section{Limitations}

There are some limitations in this study. A communitybased study rather than a hospital-based study can better project prevalence and in our settings echocardiography and other advanced diagnostics were not routinely available to diagnose malformations [21]. Further, stillbirths were not included in the study which might also have attributed to the lower prevalence. Birth defects may have been underreported as diagnosis could not have been made at birth. Many birth defects such as congenital heart defects are likely not identified at birth. In a low resource setting of Nepal, it is difficult to classify the exact type of birth defect other than the commonly seen birth defect, so we classified them as "other".

\section{Conclusion}

Birth defect is prevalent $(0.58 \%)$ among newborn babies in the same way as reported elsewhere. Various sociodemographic factors like adolescent age and disadvantaged ethnic group are associated with birth defect. Obstetric factors like being female child and number of previous birth are associated with birth defect. Babies with birth defect have high risk for birth asphyxia, neonatal infection and pre-discharge mortality at birth. There is a need to evaluate the services available for babies with birth defect for better identification and management of these babies. Birth defects are major causes of neonatal mortality and morbidity, and national surveillance is very important.

\section{Abbreviations \\ LMIC: Low and Middle Income Countries; HIC: High Income Countries; SNCU: Sick newborn care unit}

\section{Acknowledgements}

We would like to acknowledge and thank our database manager, Omkar Basnet in the data analysis and cleaning. Research team members and all the mothers who consented to the study. We would like to thank Nisso Nurova for reviewing the manuscript.

\section{Authors' contributions}

AKC, PP and AG conceptualized the study. AG and AKS conducted the first draft of the analysis. AKC reviewed the statistical analysis. PP and AKS made the first draft. $R G, H M, N R, N K C, R N C, A K C$ reviewed and revised the manuscript. All authors read and approved the final version of the manuscript.

\section{Funding}

Swedish Research Council (VR), Sweden. The funders had no role in design of the study. Open Access funding provided by Uppsala University.

\section{Availability of data and materials}

The datasets used and/or analysed during the current study are available from the corresponding author on reasonable request.

\section{Ethics approval and consent to participate}

The ethical approval for the study was taken from the Ethical Review Board (ERB) of Nepal Health Research Council (reg. no. 26-2017). Written consent was obtained from the participants enrolled in the study.

\section{Consent for publication}

Not applicable.

\section{Competing interests}

None.

\section{Author details}

${ }^{1}$ Paropakar Maternity and Women's Hospital, Ministry of Health and Population, Kathmandu, Nepal. ${ }^{2}$ Research Division, Golden Community, Lalitpur, Nepal. ${ }^{3}$ Lumbini Hospital, Provincial Ministry of Health and Population, Butwal, Nepal. ${ }^{4}$ Surkhet Provincial Hospital, Provincial Ministry of Health and Population, Surkhet, Nepal. ${ }^{5}$ Koshi Provincial Hospital, Provincial Ministry of Health and Population, Morang, Nepal. ${ }^{6}$ Department of Women's and Children's Health, Uppsala University, Dag Hammarskjölds väg 14B, Uppsala, Sweden.

Received: 6 July 2020 Accepted: 27 January 2021

Published online: 15 February 2021

References

1. Blackburn ST. Maternal, Fetal, \& Neonatal Physiology: A Clinical Perspective. In: Third edition: Sauders Elsevier; 2007.

2. Higashi H, Barendregt JJ, Kassebaum NJ, Weiser TG, Bickler SW, Vos T. The burden of selected congenital anomalies amenable to surgery in low and middle-income regions: cleft lip and palate, congenital heart anomalies and neural tube defects. Arch Dis Child. 2015;100(3):233-8.

3. World Health Organization: WHO Facts sheet on Congenital Anomalies. In. Geneva; 2016.

4. Ndibazza J, Lule S, Nampijja M, Mpairwe H, Oduru G, Kiggundu M, Akello M, Muhangi L, Elliott AM. A description of congenital anomalies among infants in Entebbe, Uganda. Birth Defects Res A Clin Mol Teratol. 2011;91(9):857-61. 
5. World Health Organization, Regional Office for South East Asia: Birth defects in South-East Asia: a public health challenge: situation analysis. . In. New Delhi; 2013.

6. World Health Organization, Regional Office for South East Asia: South East Asia Regional Neonatal- Perinatal Database. In. New Delhi; 2010.

7. Malla BK. One Year Review Study of Congenital Anatomical Malformation at Birth in Maternity Hospital (Prasutigriha), Thapathali. Kathmandu. Kathmandu Univ Med J (KUMJ). 2007:5(4):557-60.

8. Zhu H, Kartiko S, Finnell RH. Importance of gene-environment interactions in the etiology of selected birth defects. Clin Genet. 2009;75(5):409-23.

9. Queisser-Luft A, Stolz G, Wiesel A, Schlaefer K, Spranger J. Malformations in newborn: results based on 30,940 infants and fetuses from the Mainz congenital birth defect monitoring system (1990-1998). Arch Gynecol Obstet. 2002;266(3):163-7.

10. Shawky RM, Sadik DI. The role of genomics in prevention or reducing the impact of congenital malformations. Genet Couns. 2011;22(2):135-41.

11. Sitkin NA, Ozgediz D, Donkor P, Farmer DL. Congenital anomalies in lowand middle-income countries: the unborn child of global surgery. World J Surg. 2015;39(1):36-40

12. Warf BC, Alkire BC, Bhai S, Hughes C, Schiff SJ, Vincent JR, Meara JG. Costs and benefits of neurosurgical intervention for infant hydrocephalus in subSaharan Africa. J Neurosurg Pediatr. 2011;8(5):509-21.

13. Golalipour MJ, Ahmadpour-Kacho M, Ma V. Congenital malformations at a referral hospital in Gorgan, Islamic Republic of Iran. Eastern Mediterranean Health Journal. 2005;11(4):707-15.

14. Nacul L, Moorthie S, Kapila M, Zimmern R. Addressing congenital causes of disability. Lancet. 2010;375(9712):374.

15. KC A, Jha AK, Shrestha MP, Zhou H, Gurung A, Thapa J, Budhathoki SS Trends for Neonatal Deaths in Nepal (2001-2016) to Project Progress Towards the SDG Target in 2030, and Risk Factor Analyses to Focus Action. Matern Child Health J. 2020;24(Suppl 1):5-14.

16. Ministry of Health and Population Nepal: Nepal's Every Newborn Action Plan 2016-2030. In. Kathmandu; 2016.

17. Kc A, Ewald U, Basnet O, Gurung A, Pyakuryal SN, Jha BK, Bergstrom A, Eriksson L, Paudel P, Karki S, et al. Effect of a scaled-up neonatal resuscitation quality improvement package on intrapartum-related mortality in Nepal: A stepped-wedge cluster randomized controlled trial. PLoS Med. 2019;16(9):e1002900.

18. Taboo ZA-A. Prevalence and Risk Factors for Congenital Anomalies in Mosul City. Iraqi Academic Scientific Journal. 2012;11(4):458-70.

19. Ameen SK, Alalaf SK, Shabila NP. Pattern of congenital anomalies at birth and their correlations with maternal characteristics in the maternity teaching hospital, Erbil city. Iraq. BMC Pregnancy Childbirth. 2018;18(1):501.

20. Mashhadi Abdolahi H, Kargar Maher MH, Afsharnia F, Dastgiri S. Prevalence of congenital anomalies: a community-based study in the northwest of iran. ISRN Pediatr. 2014;2014:920940.

21. Sarkar S, Patra C, Dasqupta MK, Nayek K, Karmakar PR. Prevalence of congenital anomalies in neonates and associated risk factors in a tertiary care hospital in eastern India. J Clin Neonatol. 2013;2(3):131-4.

22. El Koumi EAAB MA, Lebda I. Pattern of congenital anomalies in newborn: a hospital-based study. Pediatric Report. 2013;5:1.

23. Khatami F. GAM: Survey of congenital major malformation in 10,000 newborns. Iranian Journal of Pediatrics. 2005;15(4).

24. Suguna Bai NS, Mascarene M, Syamalan K, Nair PM. An etiological study of congenital malformation in the newborn. Indian Pediatr. 1982:19(12):1003-7.

25. Croen LA, Shaw GM. Young maternal age and congenital malformations: a population-based study. Am J Public Health. 1995;85(5):710-3.

26. Pushpal Chowdhury RKPD, Singh LB, Thakare AS, Tamang ZD, Debroy S, Bhutia TZ, Banik P. Clinical Study on Congenital Malformations At Birth in A Tertiary Level Hospital in North-East India. IOSR Journal of Dental and Medical Sciences. 2017;16(1):24-7.

27. Chen CJ, Wang CJ, Yu MW, Lee TK: Perinatal mortality and prevalence of major congenital malformations of twins in Taipei city. Acta Genet Med Gemellol (Roma) 1992, 41(2-3):197-203.

28. CGC DC. Risk factors associated with congenital anomalies in children. ARS Medica Tomitana. 2015:21(2)

29. Pharoah POD. Causal Hypothesis for Some Congenital Anomalies. Twin Res Hum Genet. 2005;8(6):543-50.

30. Perveen F, Tyyab S. Frequency and pattern of distribution of congenital anomalies in the newborn and associated maternal risk factors. J Coll Physicians Surg Pak. 2007;17(6):340-3.
31. Benjamin BG, Ethen MK, Van Hook CL, Myers CA, Canfield MA: Gastroschisis prevalence in Texas 1999-2003. Birth Defects Res A Clin Mol Teratol 2010, 88(3):178-185

32. Duong HT, Hoyt AT, Carmichael SL, Gilboa SM, Canfield MA, Case A, McNeese ML, Waller DK. National Birth Defects Prevention S: Is maternal parity an independent risk factor for birth defects? Birth Defects Res A Clin Mol Teratol. 2012;94(4):230-6.

33. Hernandez-Diaz S, Werler MM, Walker AM, Mitchell AA. Folic acid antagonists during pregnancy and the risk of birth defects. N Engl J Med. 2000;343(22):1608-14.

34. Egbe A, Lee S, Ho D, Uppu S. Effect of Race on the Prevalence of Congenital Malformations among Newborns in the United States. Ethn Dis. 2015;25(2):226-31.

35. Egbe A, Uppu S, Lee S, Stroustrup A, Ho D, Srivastava S. Congenital malformations in the newborn population: a population study and analysis of the effect of sex and prematurity. Pediatr Neonatol. 2015;56(1):25-30.

36. Madhabi Lata Shuma SH, Bidyut Kanti Datta, : Epidemiology of Congenital Anomalies among the Children born in Different Hospitals under Sylhet Division in Bangladesh- a Retrospective Study. Dhaka University Journal of Pharmaceutical Sciences 2015, 14(2).

37. Hena Rani Barua RRB, Dhar SR, Barua S, Barua AK, Prasad I, Jalil Ansari MA, Begum K. Congenital Anomaly in 100 Pregnant Women in a District Hospital of Bangladesh. J Dhaka Medical College. 2017;25(2).

38. James WH. Potential of the Hormonal Hypothesis of Sex Ratio to Explain the Unusual Sex Ratios Typical of Some Malformations. Teratology. 2002; 66(3).

39. Hay S. Sex differences in the incidence of certain congenital malformations: a review of the literature and some new data. Teratology. 1971 Aug;4(3): 277-86.

40. Deak KL, Siegel DG, George TM, Gregory S, Ashley-Koch A, Speer MC. NTD Collaborative Group. Further evidence for a maternal genetic effect and a sex-influenced effect contributing to risk for human neural tube defects. Clin Mol Teratol. 2008 Oct:82(10):662-9.

41. Sandeep Sachdeva SN, Bhalla K, Sachdeva R. Gross Congenital Malformation at Birth in a Government Hospital. Indian Journal of Public Health. 2014; $58(1)$

\section{Publisher's Note}

Springer Nature remains neutral with regard to jurisdictional claims in published maps and institutional affiliations.
Ready to submit your research? Choose BMC and benefit from:

- fast, convenient online submission

- thorough peer review by experienced researchers in your field

- rapid publication on acceptance

- support for research data, including large and complex data types

- gold Open Access which fosters wider collaboration and increased citations

- maximum visibility for your research: over $100 \mathrm{M}$ website views per year

At $\mathrm{BMC}$, research is always in progress.

Learn more biomedcentral.com/submissions 